\title{
Advances in the fabrication of superhydrophobic polymeric surfaces by polymer molding processes
}

\author{
Khosrow Maghsoudi*, Elham Vazirinasab, Gelareh Momen, Reza Jafari \\ Department of Applied Sciences, University of Quebec in Chicoutimi (UQAC) \\ 555, boul. de l'Université, Chicoutimi, Québec, G7H 2B1, Canada \\ *E-mail: Khosrow.maghsoudil@uqac.ca
}

Table S1 represents polymer molding processes to produce various superhydrophobic polymer materials with the associated processing parameters. 


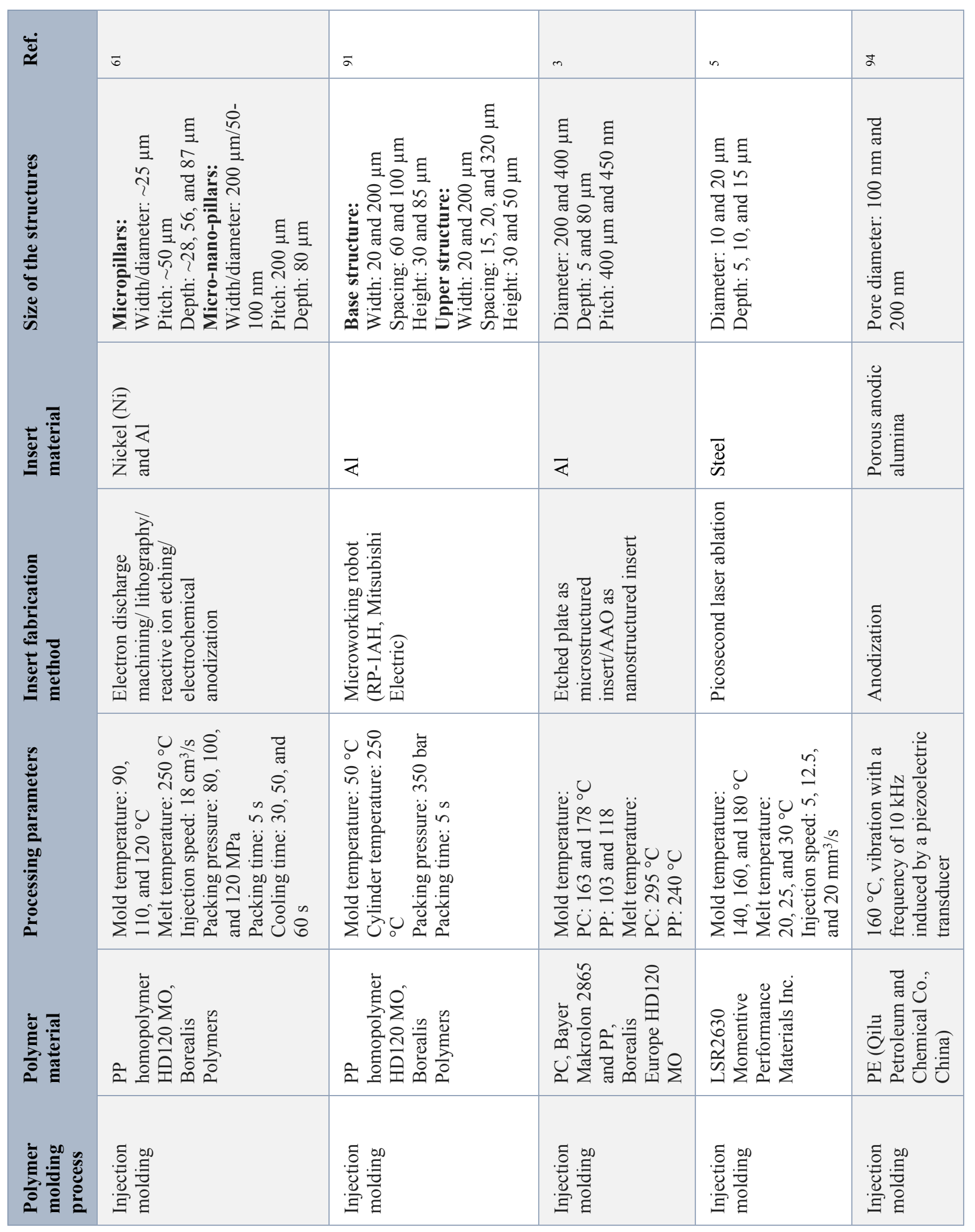




\begin{tabular}{|c|c|c|c|c|}
\hline 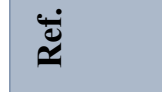 & $\begin{array}{l}\infty \\
f \\
f\end{array}$ & $n$ & $=$ & $\infty$ \\
\hline 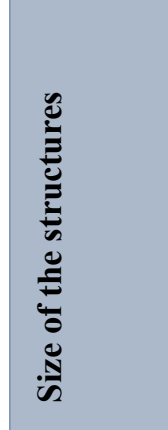 & 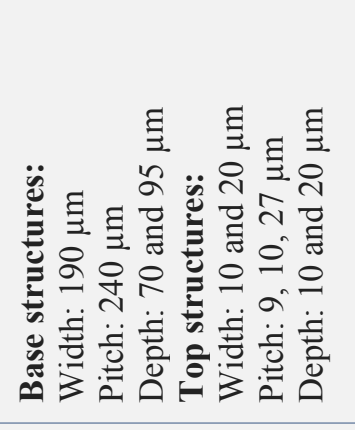 & 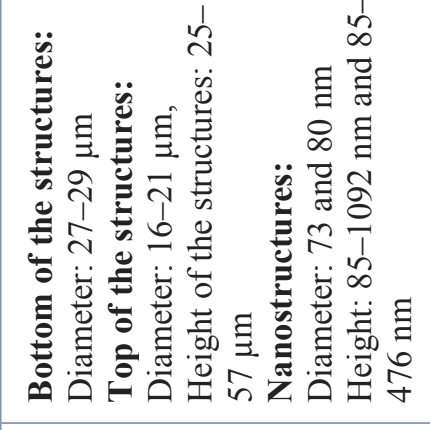 & 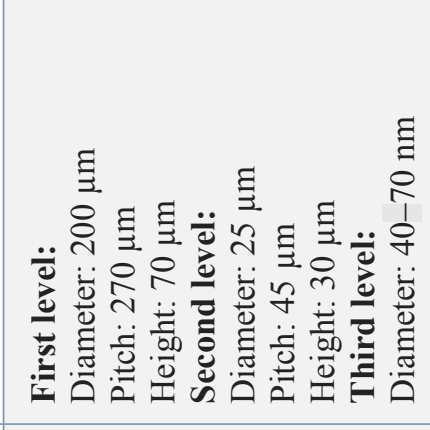 & 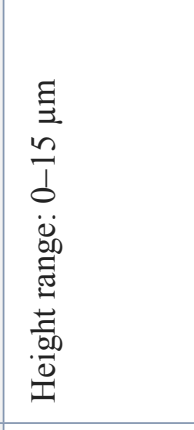 \\
\hline 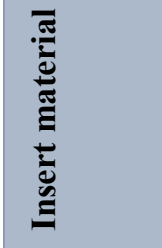 & ষ & z & $\bar{\varangle}$ & $\bar{z}$ \\
\hline 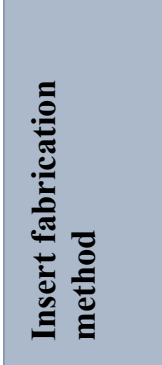 & 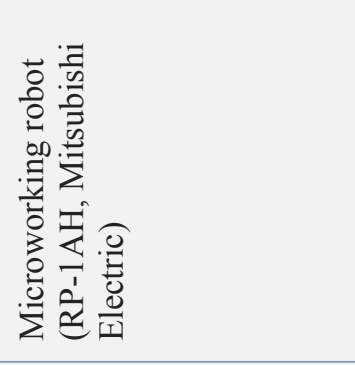 & 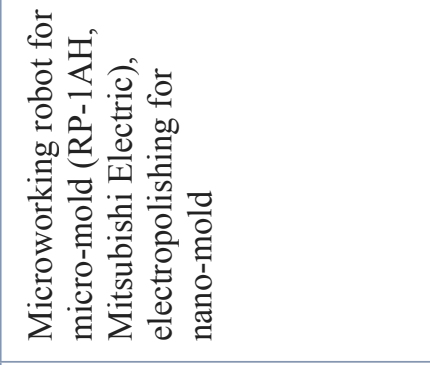 & 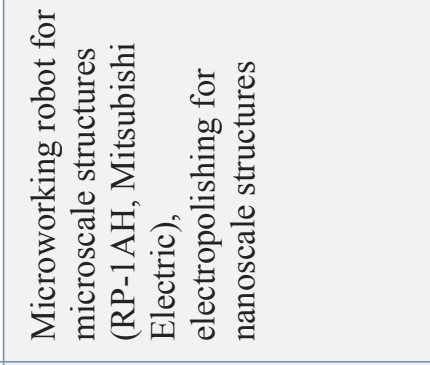 & 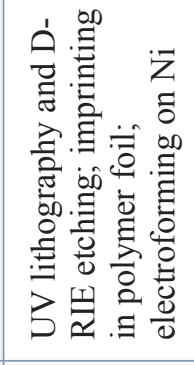 \\
\hline 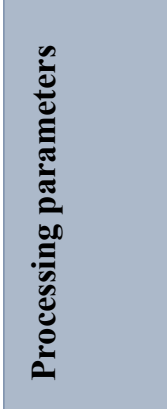 & 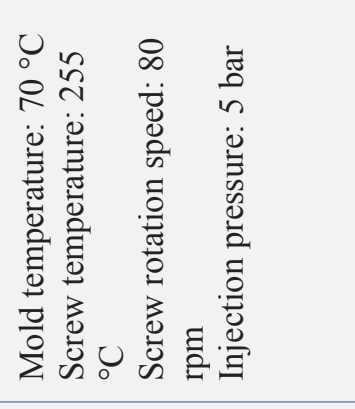 & 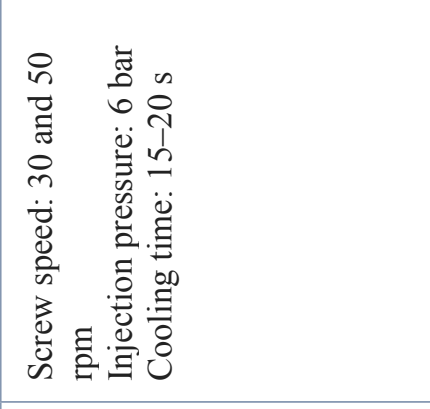 & 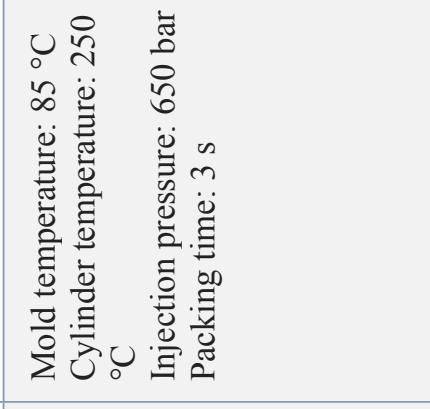 & 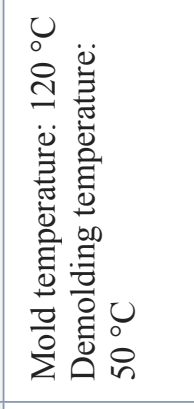 \\
\hline 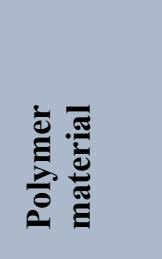 & 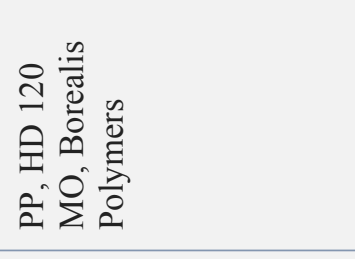 & 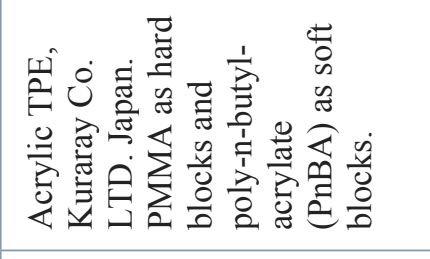 & 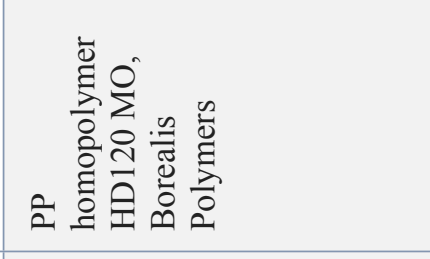 & 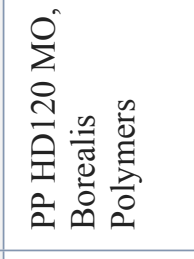 \\
\hline 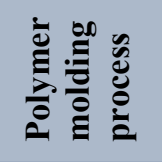 & 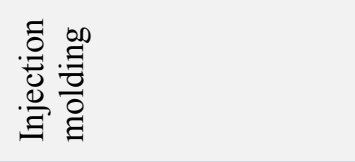 & 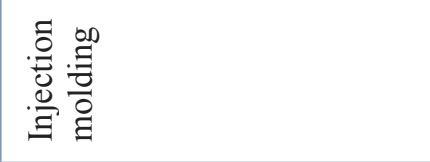 & 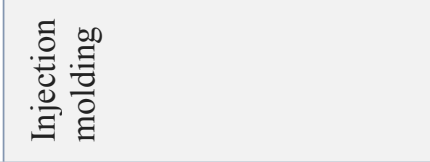 & 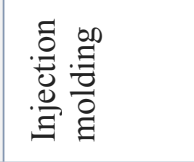 \\
\hline
\end{tabular}




\begin{tabular}{|c|c|c|c|c|c|c|c|}
\hline$\ddot{\ddot{\Xi}}$ & $\approx$ & - & $\vec{\infty}$ & $\infty$ & $\stackrel{\infty}{\circ}$ & $\stackrel{\Xi}{=}$ & $\stackrel{\infty}{\infty}$ \\
\hline 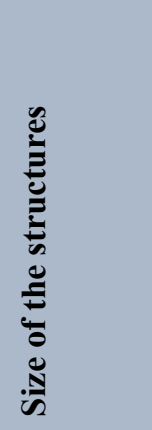 & 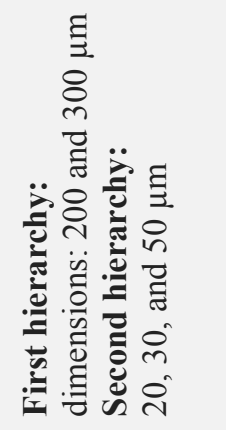 & 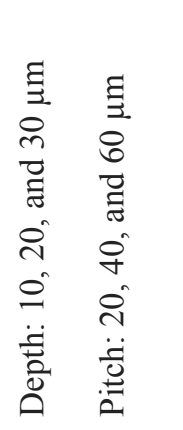 & 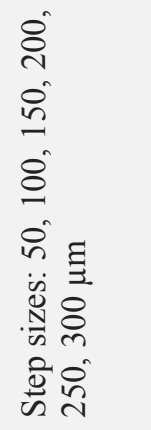 & $\mathbb{z}$ & 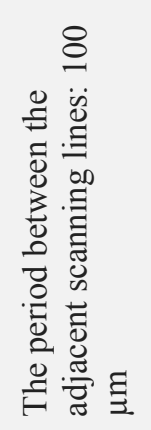 & 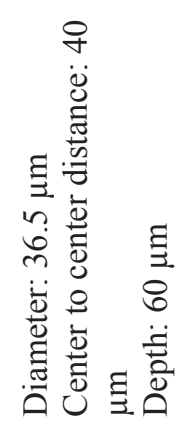 & 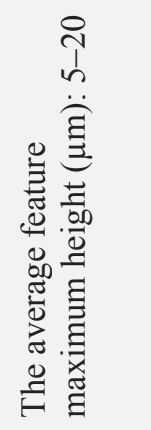 \\
\hline 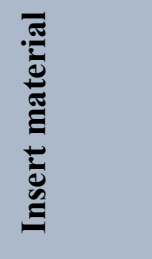 & ব & $\tilde{z}$ & ব & ব & $F$ & 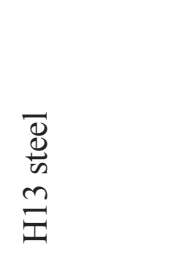 & 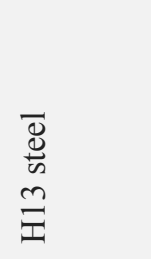 \\
\hline 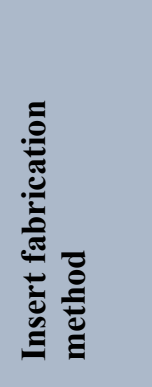 & 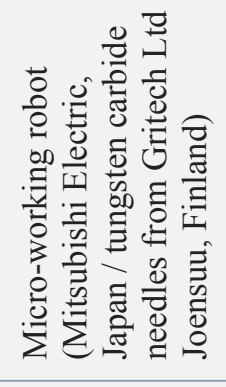 & 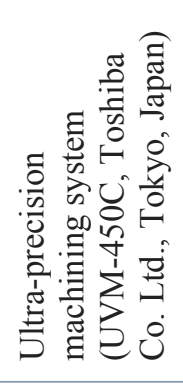 & 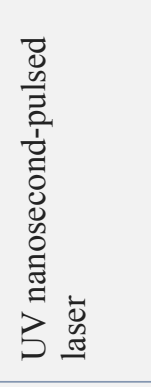 & 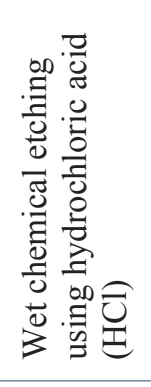 & 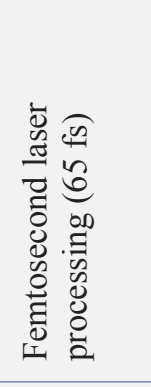 & 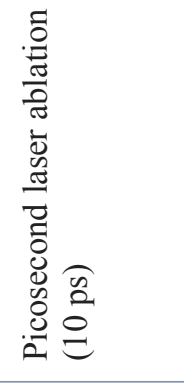 & 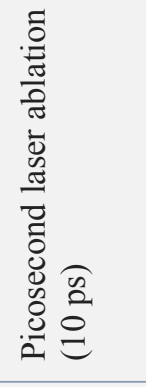 \\
\hline 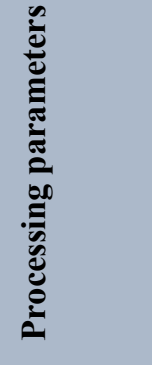 & $\frac{\mathbb{z}}{2}$ & 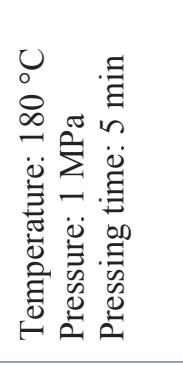 & 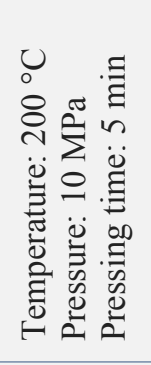 & 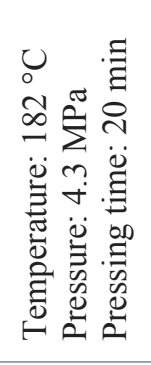 & 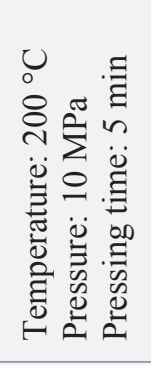 & 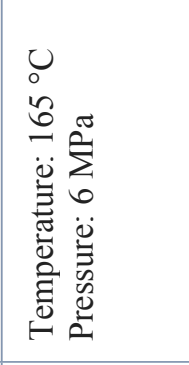 & 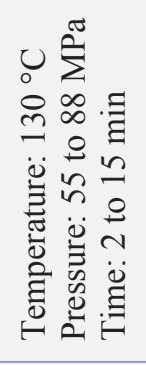 \\
\hline 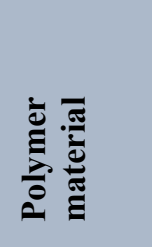 & 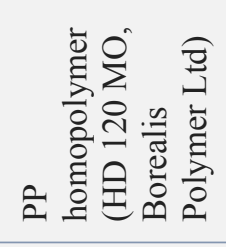 & 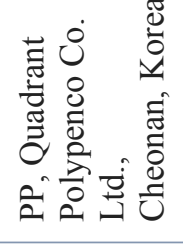 & $\approx$ & 空 & 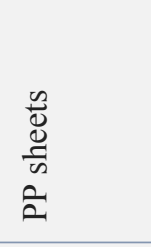 & 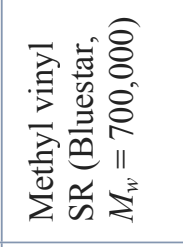 & $\vec{E}$ \\
\hline 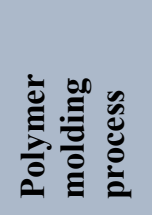 & 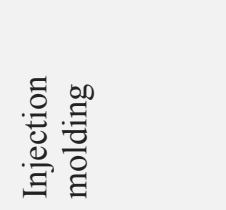 & 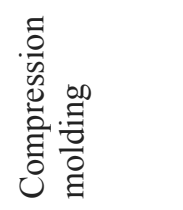 & 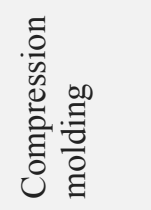 & 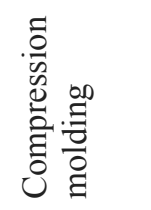 & 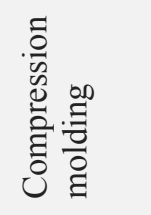 & 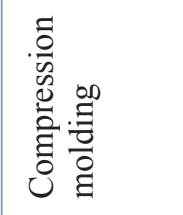 & 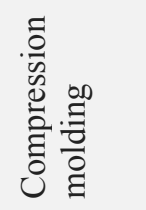 \\
\hline
\end{tabular}




\begin{tabular}{|c|c|c|c|c|c|c|c|}
\hline 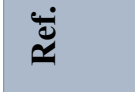 & \& & $\Xi$ & F & $\stackrel{\varrho}{\circ}$ & - & 2 & 5 \\
\hline$\overline{0}$ & 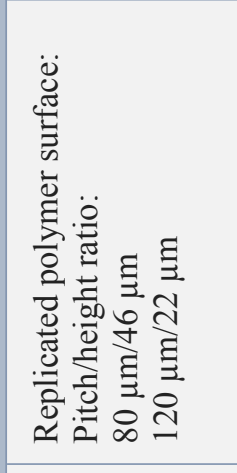 & 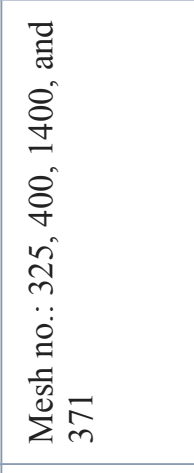 & 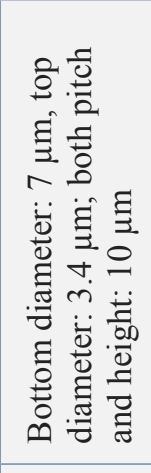 & 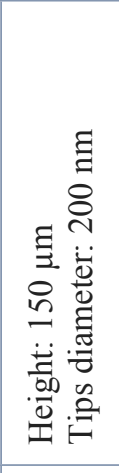 & 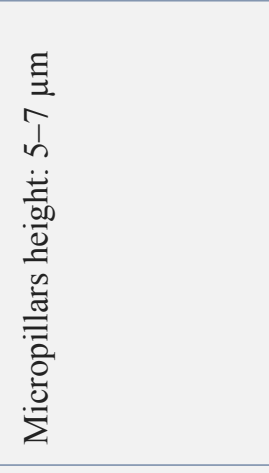 & 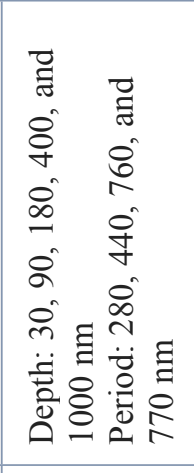 & 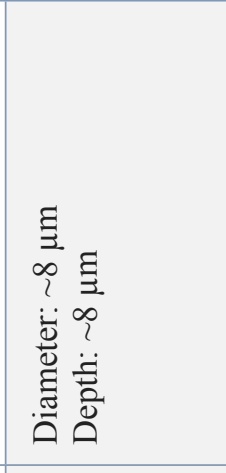 \\
\hline$\Xi$ & 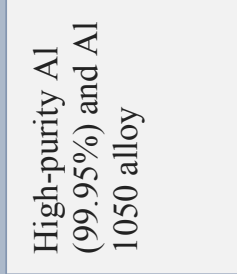 & 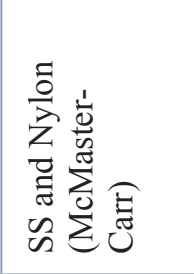 & $\bar{z}$ & 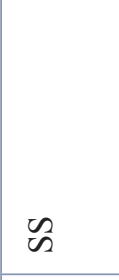 & 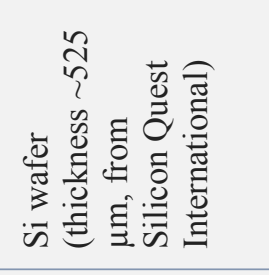 & $\dot{z}$ & 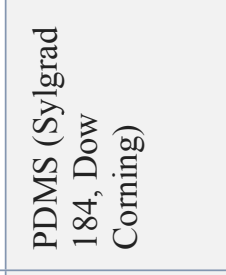 \\
\hline 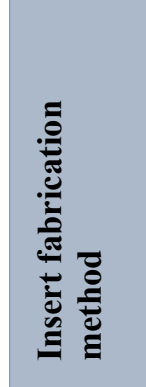 & 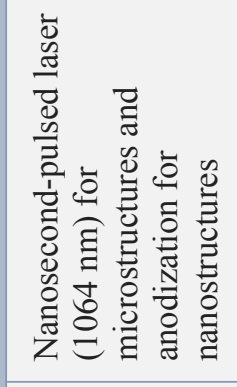 & 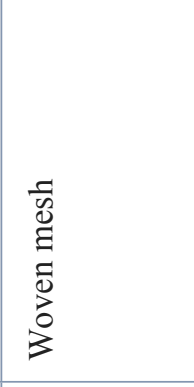 & $\mathbb{z}$ & 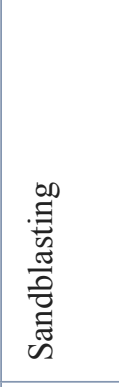 & 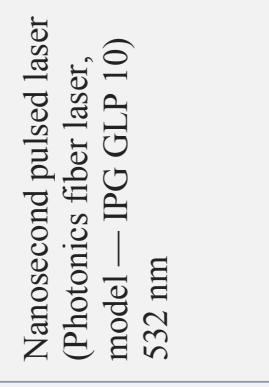 & 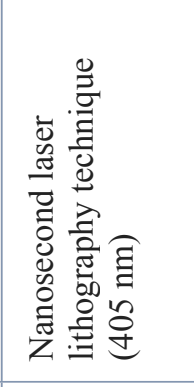 & 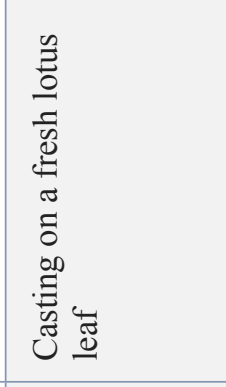 \\
\hline 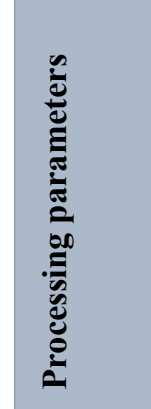 & 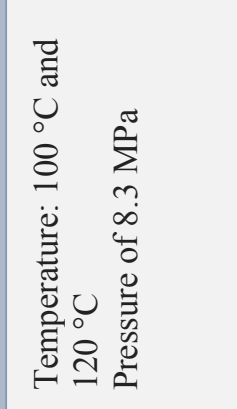 & 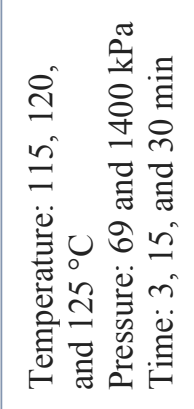 & 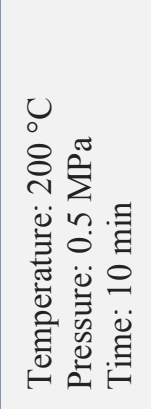 & 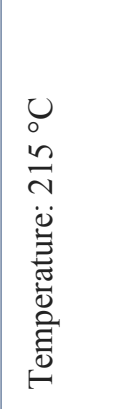 & 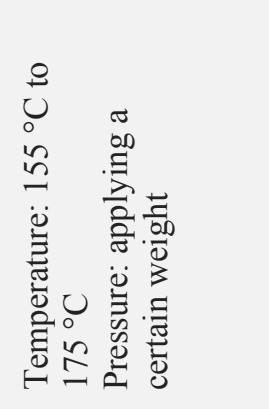 & 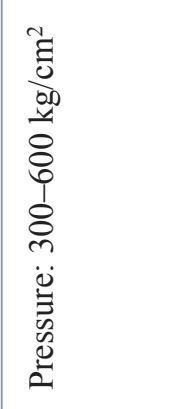 & 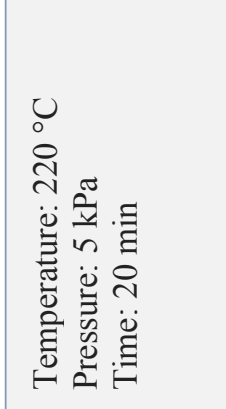 \\
\hline 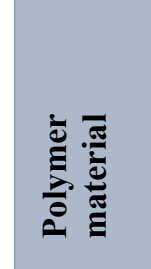 & 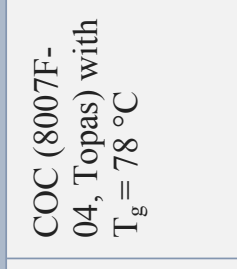 & 言 & 罯 & $\stackrel{0}{0}$ & 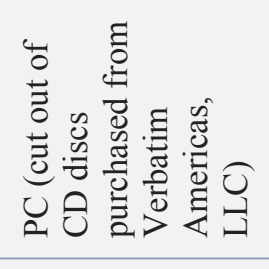 & 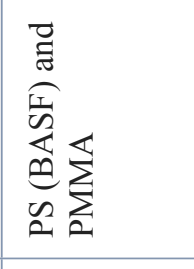 & 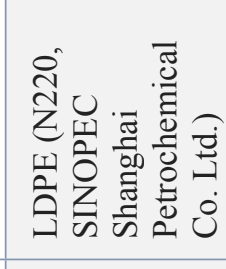 \\
\hline 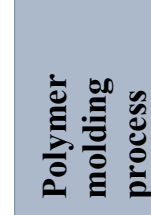 & 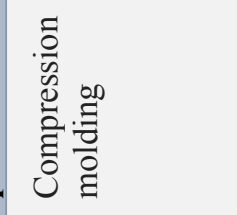 & 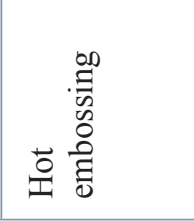 & 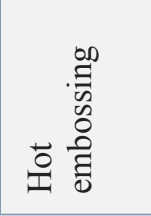 & 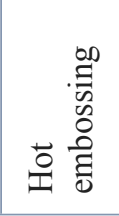 & 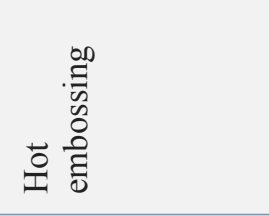 & 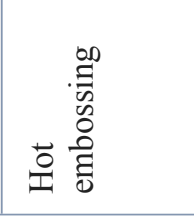 & 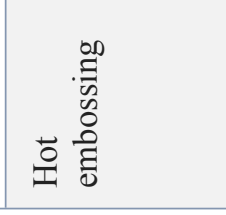 \\
\hline
\end{tabular}




\begin{tabular}{|c|c|c|c|c|c|}
\hline 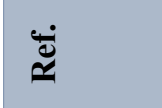 & $n$ & $\because$ & s & $:$ & $\Xi$ \\
\hline 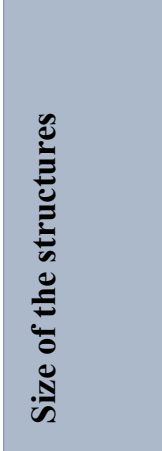 & 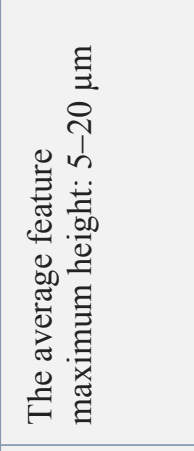 & 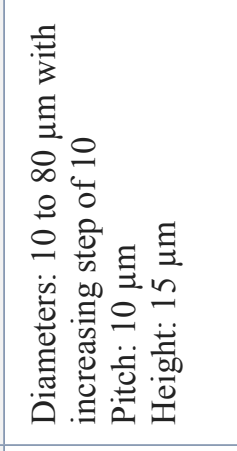 & 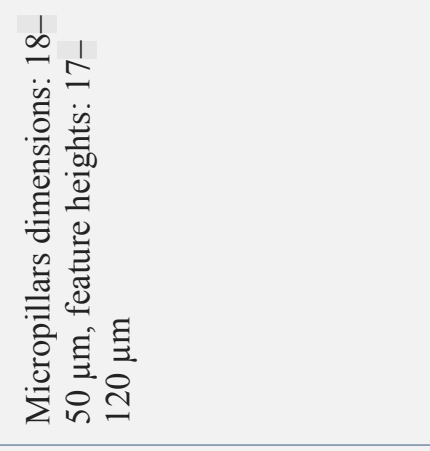 & 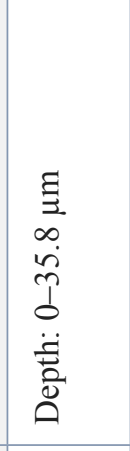 & 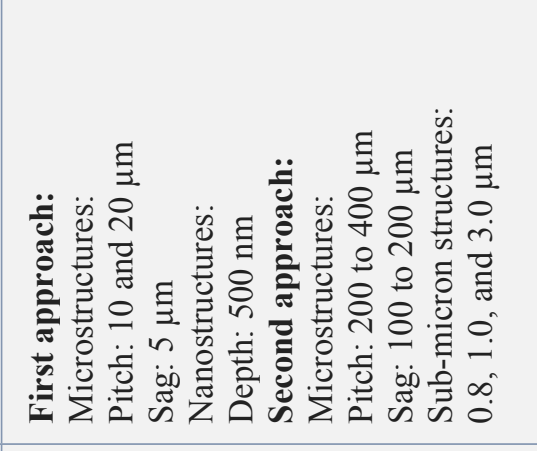 \\
\hline 吾 & ব & 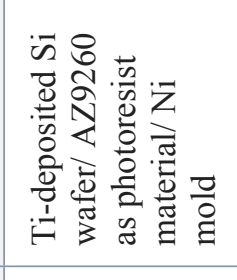 & $\begin{array}{l}\frac{b}{w} \\
w \\
w\end{array}$ & $\begin{array}{l}\vec{E} \\
\vec{v} \\
\vec{E} \\
\dot{n}\end{array}$ & 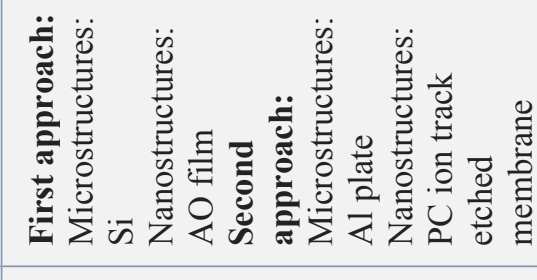 \\
\hline 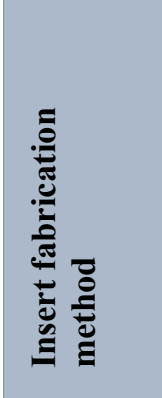 & 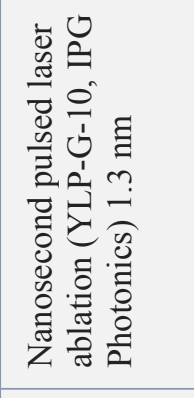 & 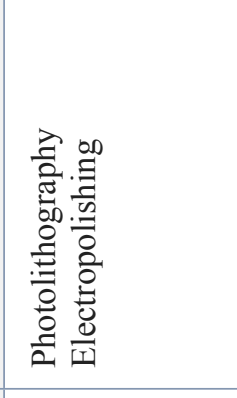 & 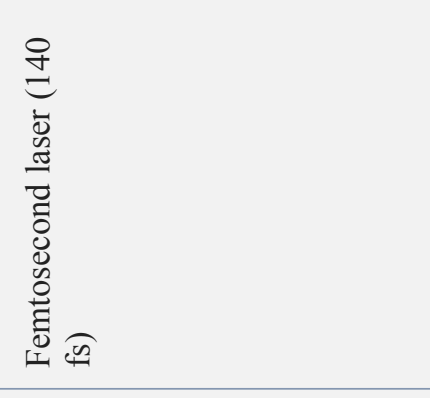 & 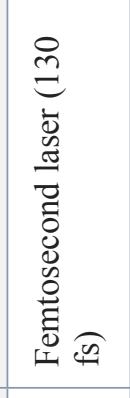 & 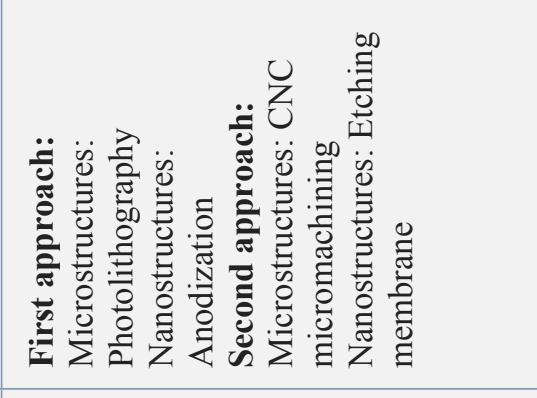 \\
\hline 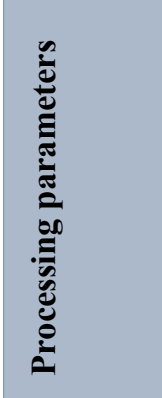 & 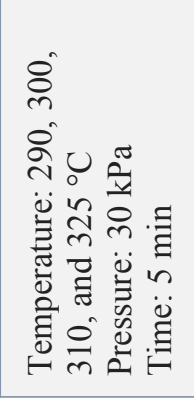 & 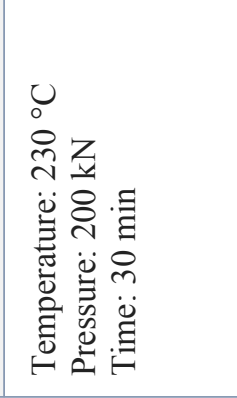 & 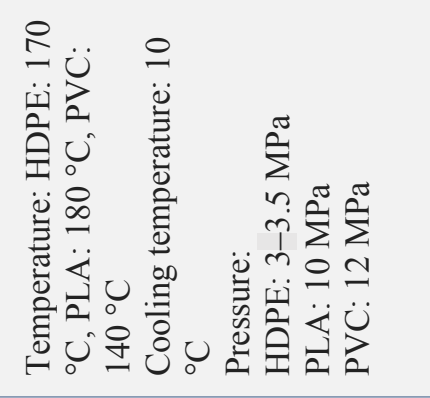 & 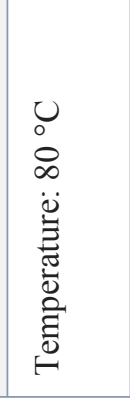 & 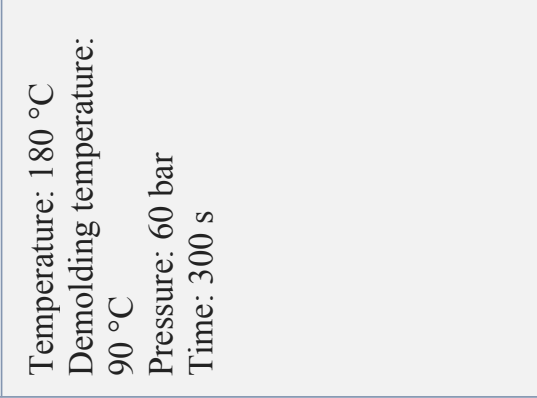 \\
\hline 彦 & 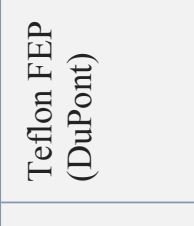 & $\Xi$ & 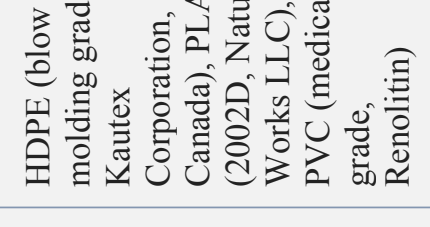 & $\sum_{a}^{n}$ & $\tilde{\Xi}$ \\
\hline 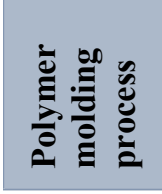 & 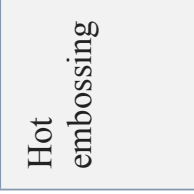 & 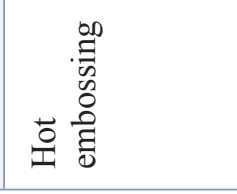 & 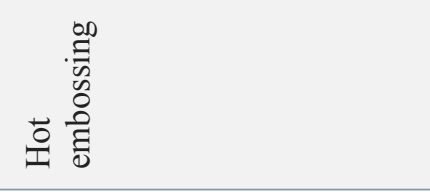 & 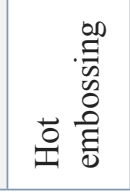 & 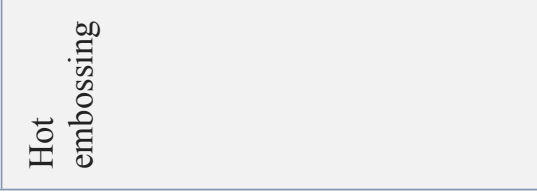 \\
\hline
\end{tabular}




\begin{tabular}{|c|c|c|c|c|}
\hline 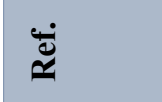 & $\underline{\underline{t}}$ & 8 & $\stackrel{\circ}{\cong}$ & $\stackrel{\mathscr{2}}{=}$ \\
\hline D. & 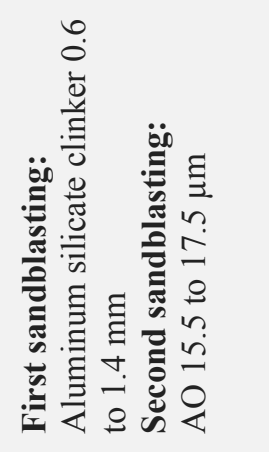 & 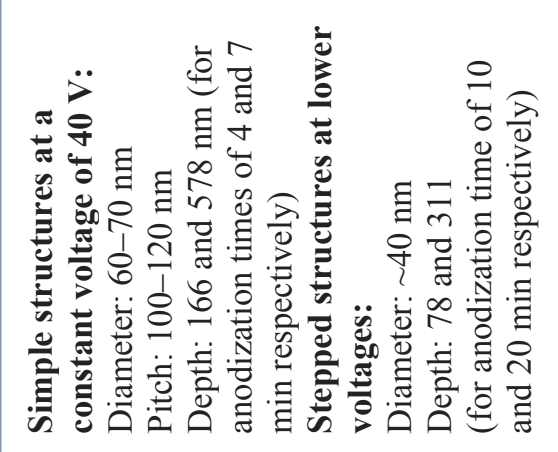 & & 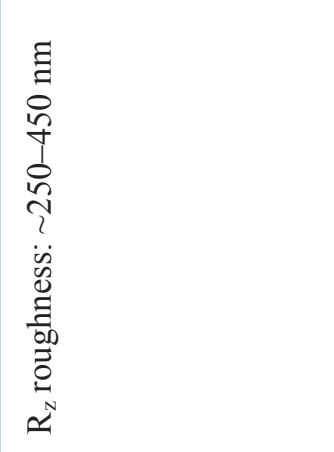 \\
\hline 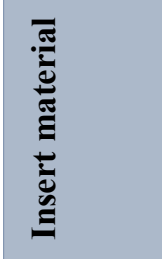 & 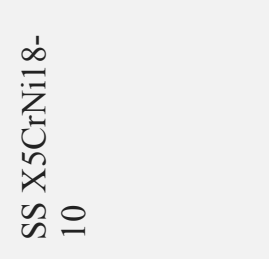 & 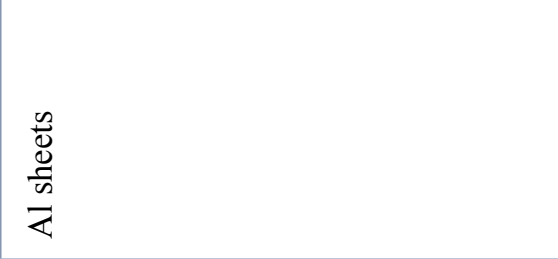 & & $\bar{z}$ \\
\hline 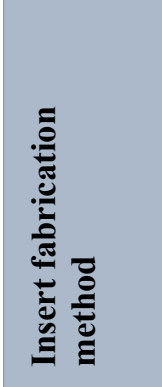 & 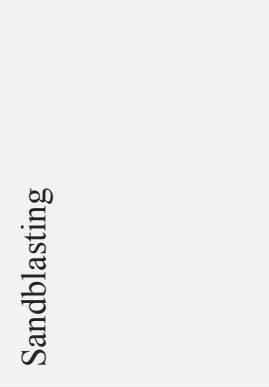 & 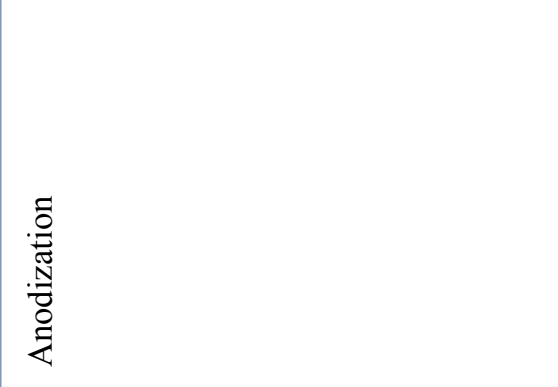 & 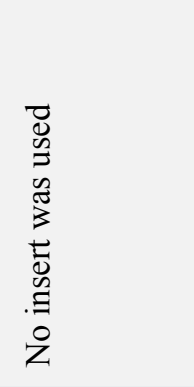 & 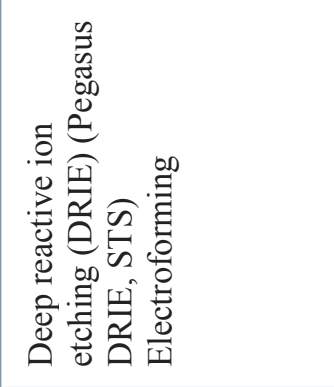 \\
\hline 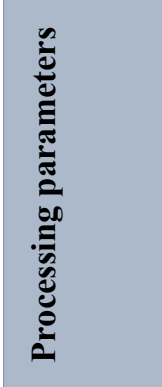 & 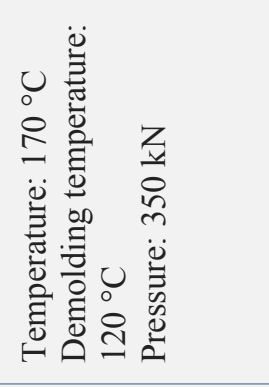 & 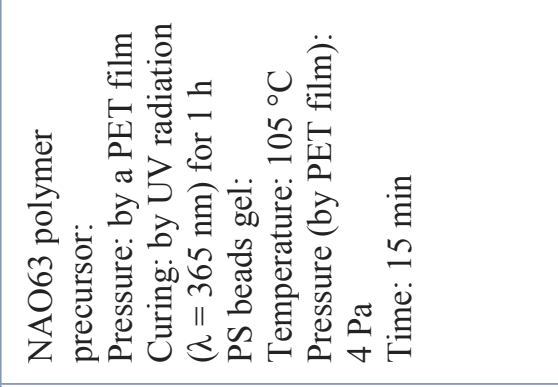 & 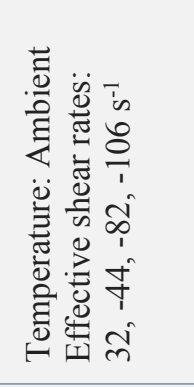 & 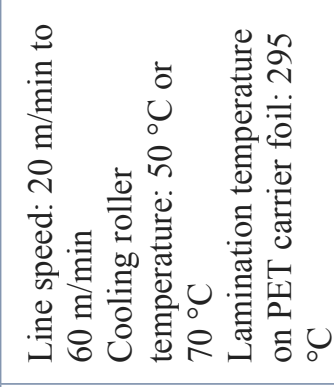 \\
\hline 列 & 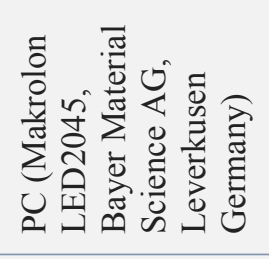 & 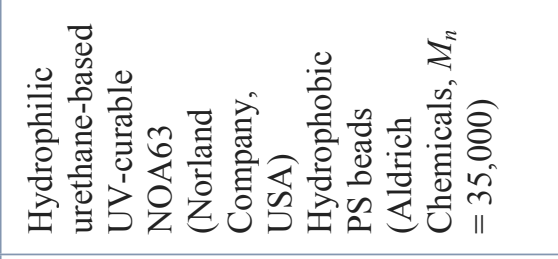 & 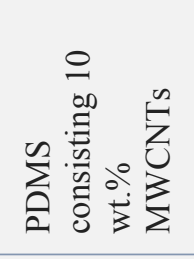 & 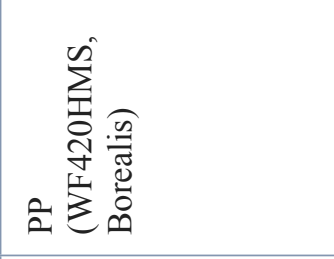 \\
\hline 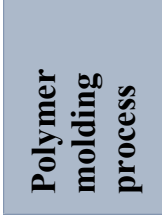 & 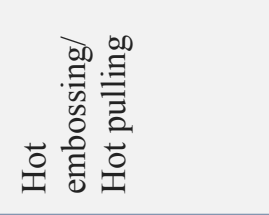 & 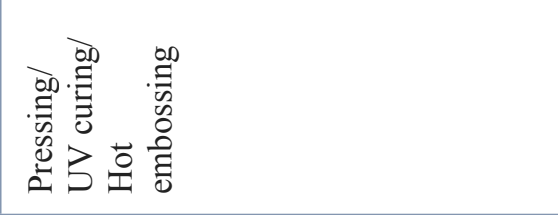 & 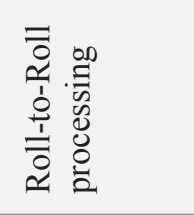 & 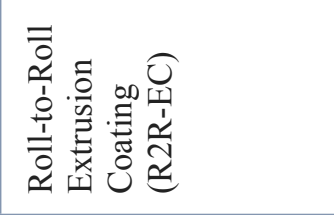 \\
\hline
\end{tabular}




\begin{tabular}{|c|c|c|c|c|c|}
\hline 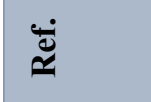 & 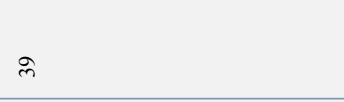 & 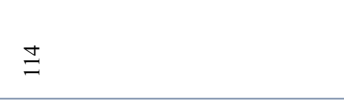 & + & $\cong$ & $\cong$ \\
\hline 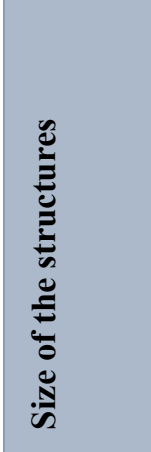 & 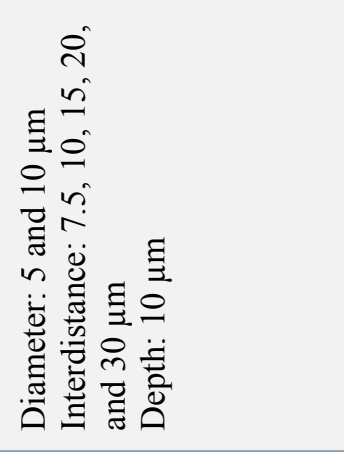 & 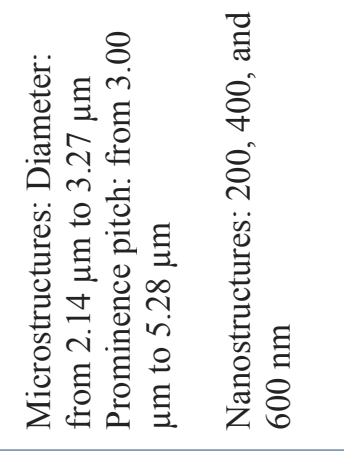 & 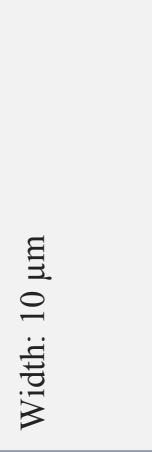 & & 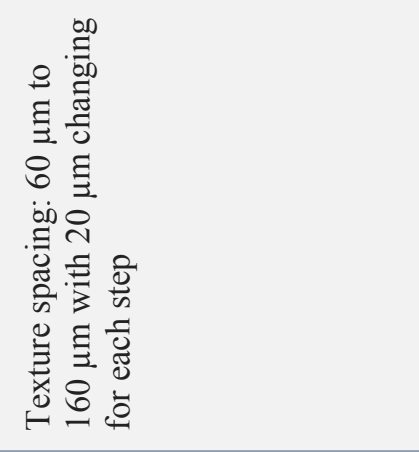 \\
\hline 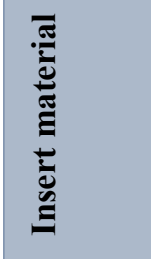 & $i$ & 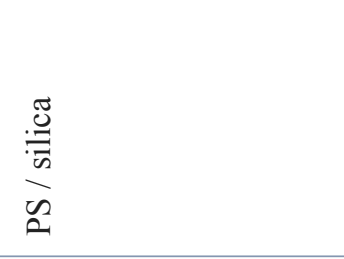 & 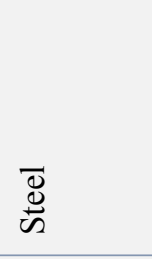 & 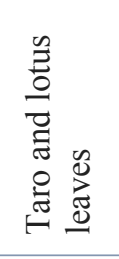 & 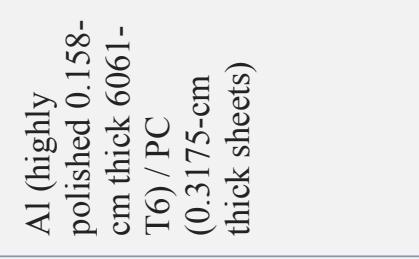 \\
\hline 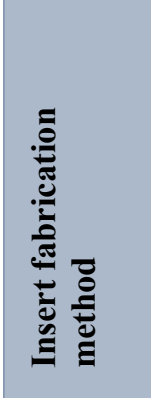 & 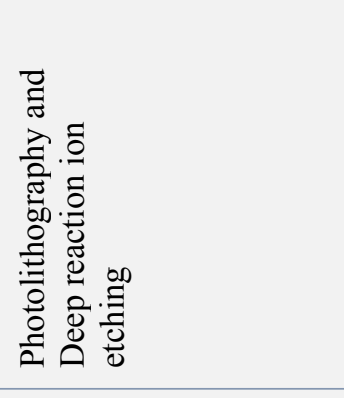 & 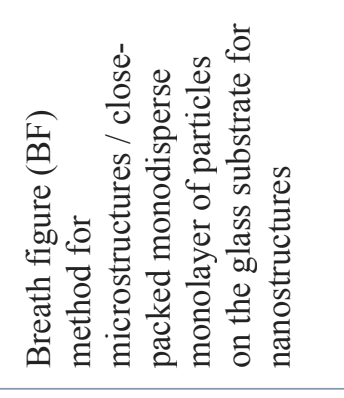 & 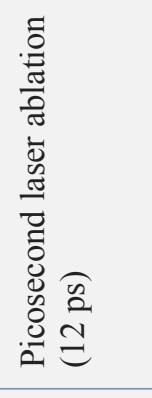 & 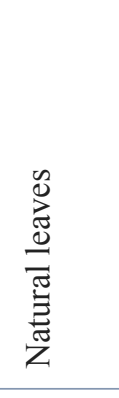 & 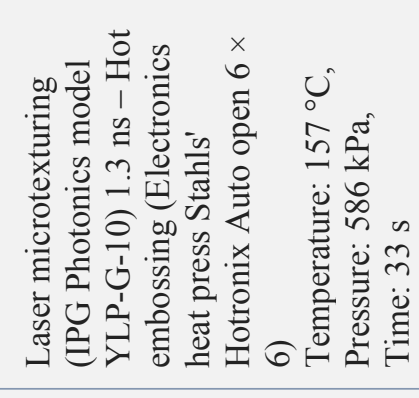 \\
\hline 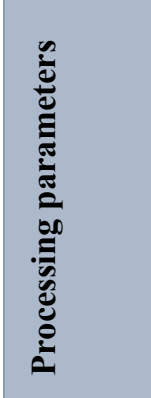 & 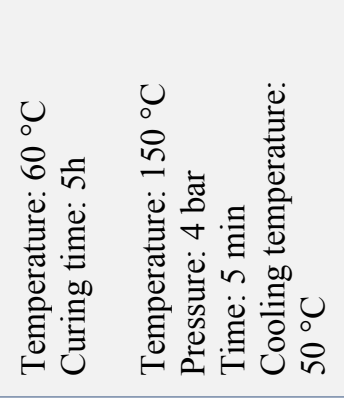 & 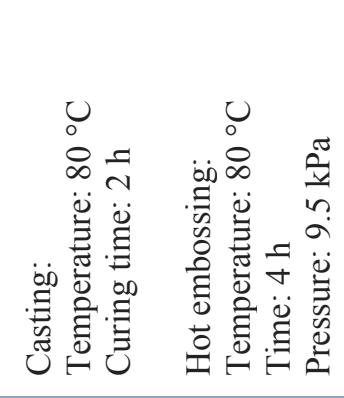 & 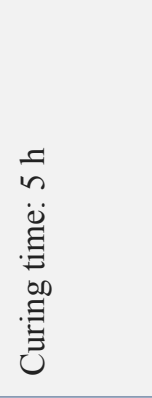 & 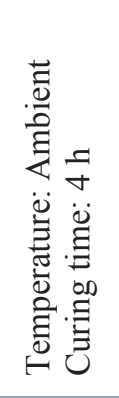 & 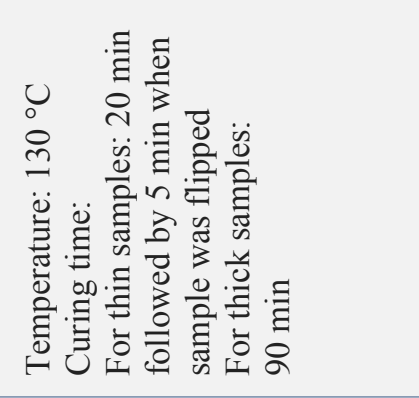 \\
\hline 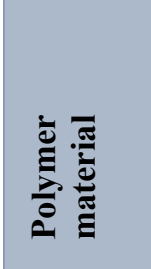 & 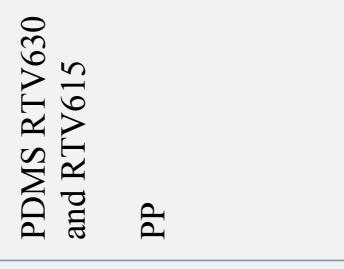 & ẩ & 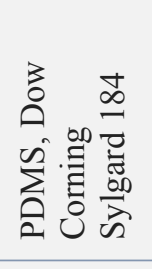 & $\sum_{0}^{n}$ & $\sum_{\hat{a}}^{n}$ \\
\hline 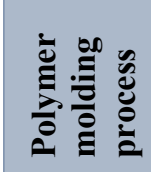 & 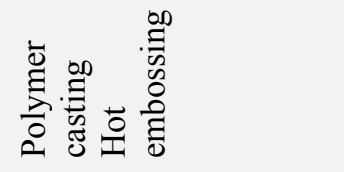 & 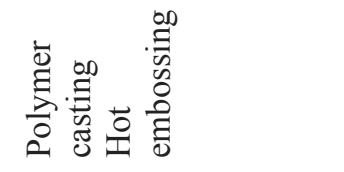 & 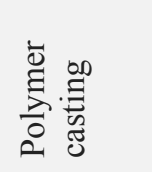 & 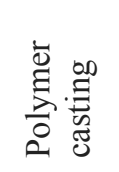 & 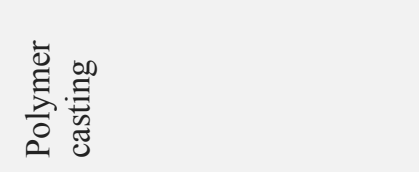 \\
\hline
\end{tabular}




\begin{tabular}{|c|c|c|c|c|c|}
\hline$\ddot{\ddot{\Xi}}$ & $\Phi$ & $\Xi$ & 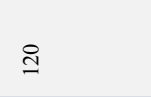 & $\because 8$ & 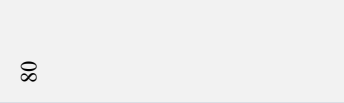 \\
\hline 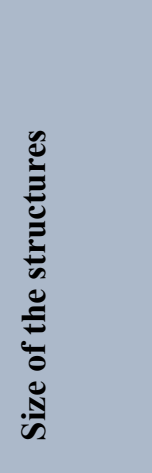 & 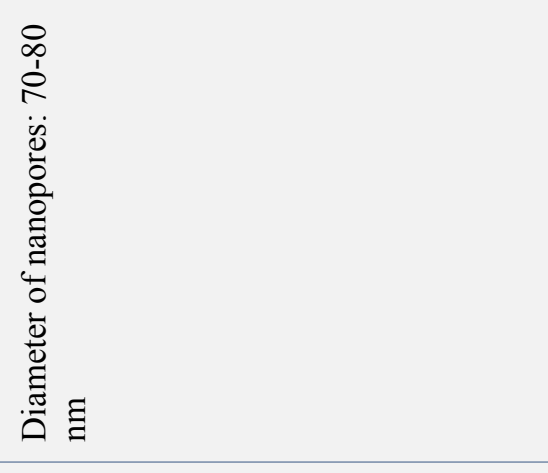 & 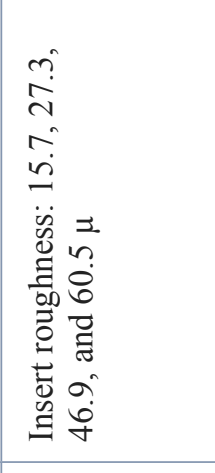 & 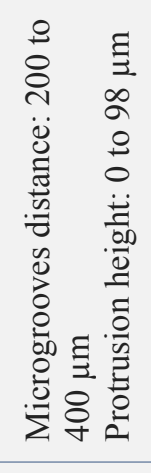 & 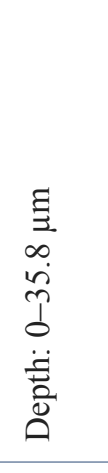 & 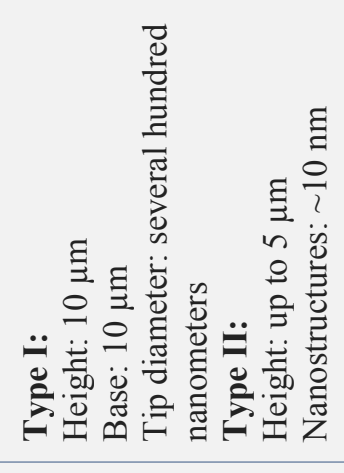 \\
\hline 焉 & ব & 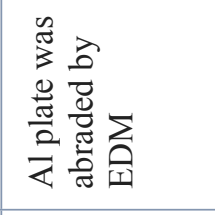 & $\approx$ & $\begin{array}{l}\vec{F} \\
\vec{G} \\
\vec{E} \\
\dot{\omega}\end{array}$ & 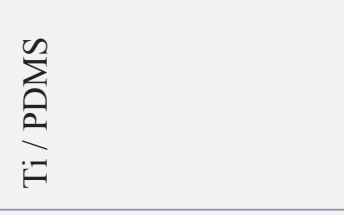 \\
\hline 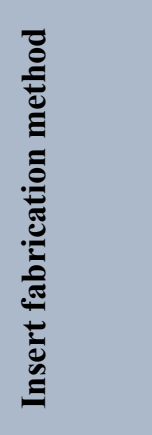 & 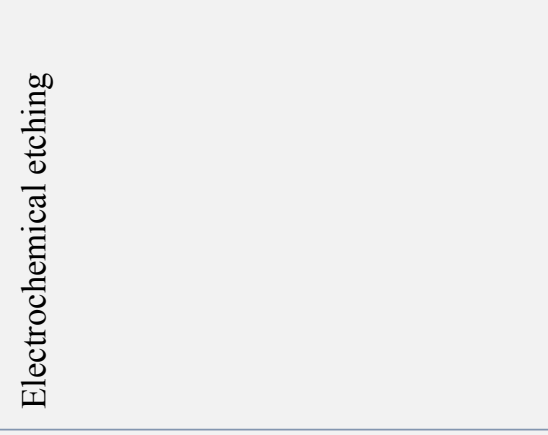 & 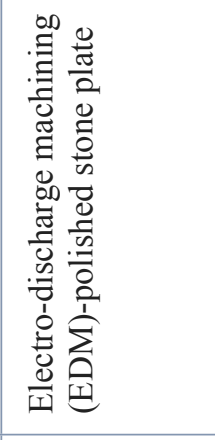 & 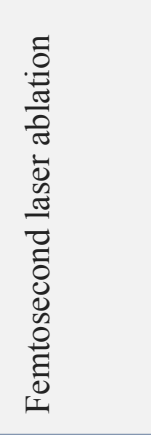 & 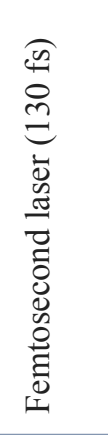 & 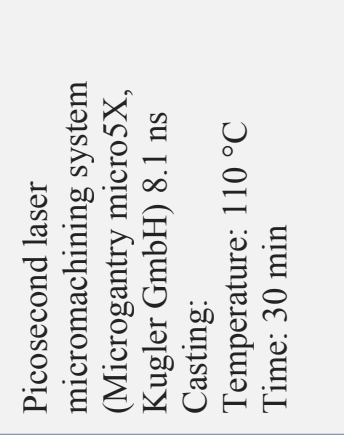 \\
\hline 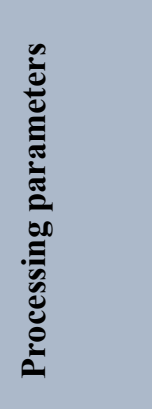 & 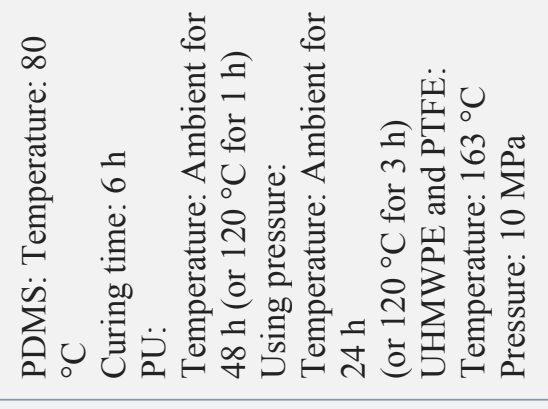 & 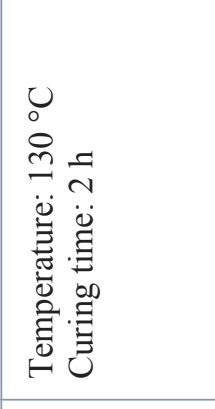 & 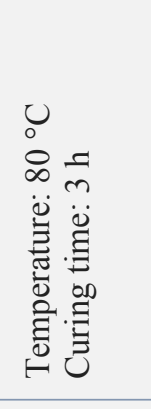 & 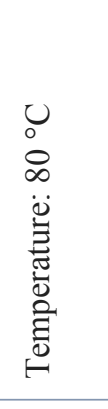 & 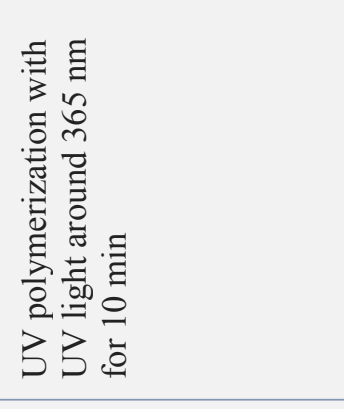 \\
\hline 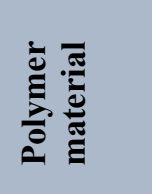 & 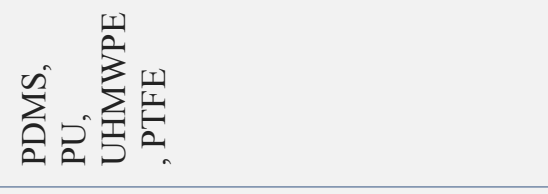 & 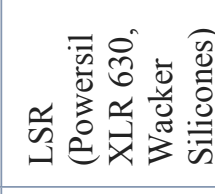 & $\sum_{2}^{n}$ & $\sum_{\hat{a}}^{\infty}$ & 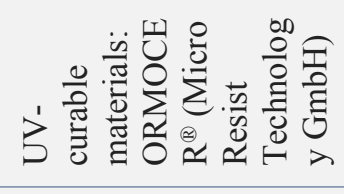 \\
\hline 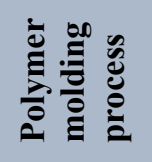 & 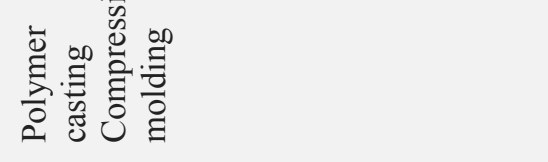 & 总. & 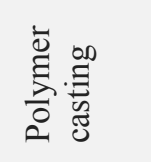 & 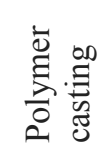 & 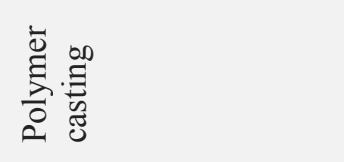 \\
\hline
\end{tabular}




\begin{tabular}{|c|c|c|c|c|c|}
\hline 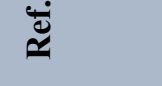 & $\infty$ & : & $\infty$ & $\underset{\infty}{ \pm}$ & \pm \\
\hline 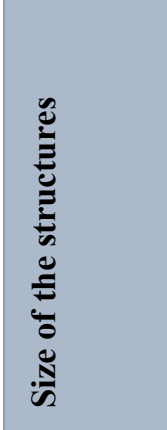 & 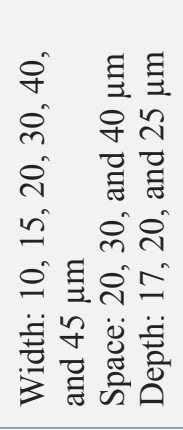 & 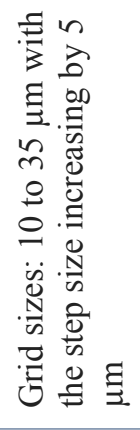 & 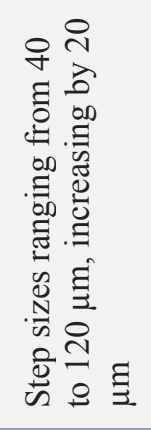 & 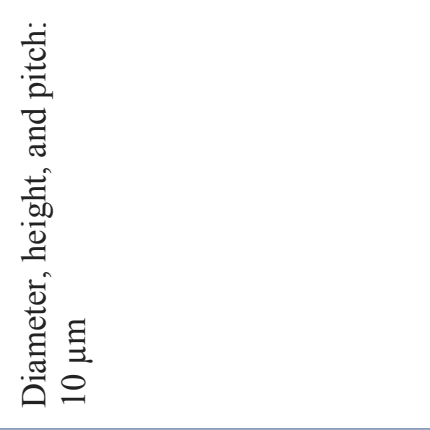 & 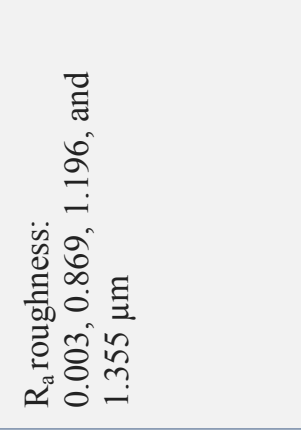 \\
\hline 吾 & 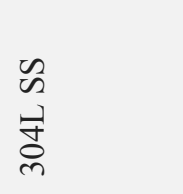 & $\mathbb{z}$ & ব & $\begin{array}{l}n \\
\sum_{0}^{n} \\
\\
\text { in }\end{array}$ & 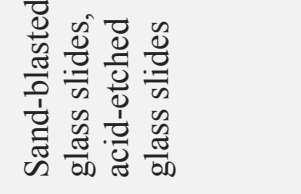 \\
\hline 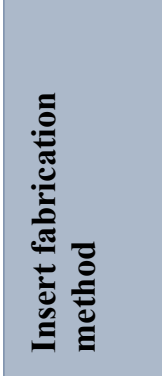 & 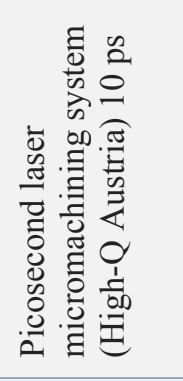 & 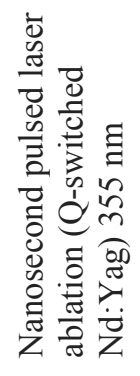 & 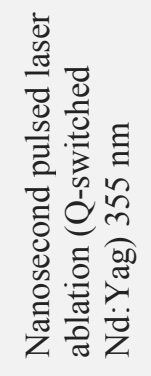 & 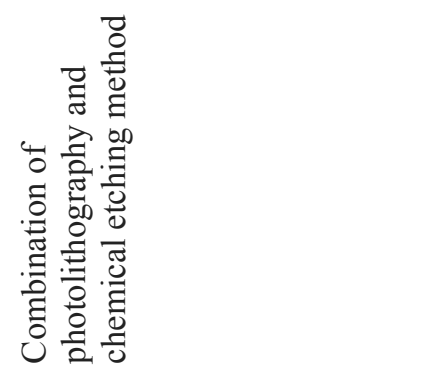 & 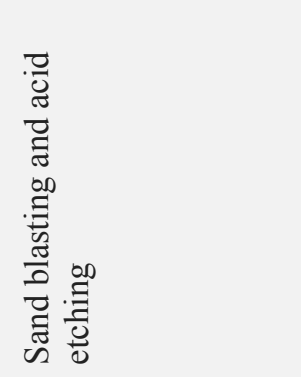 \\
\hline 蒂 & 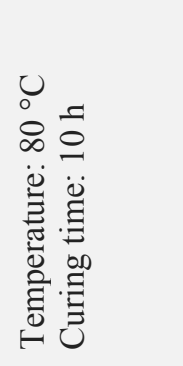 & 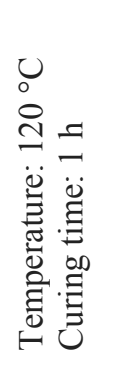 & 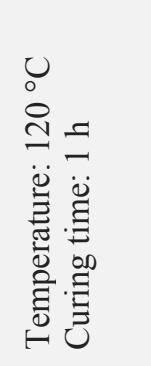 & 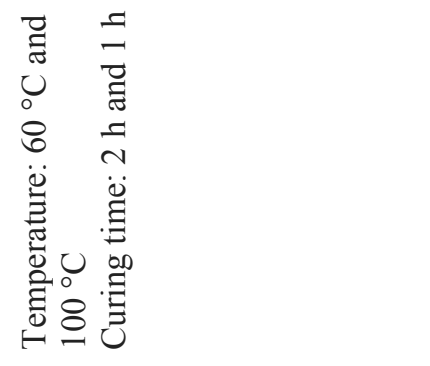 & 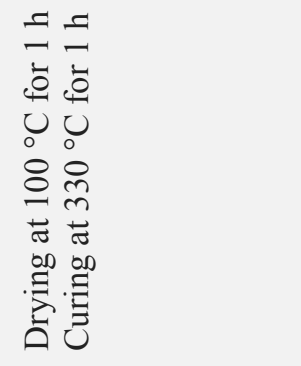 \\
\hline 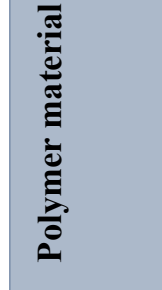 & 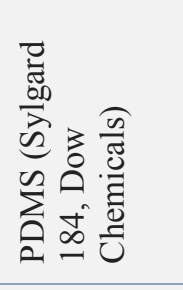 & 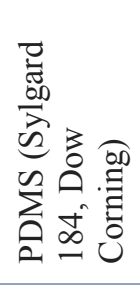 & 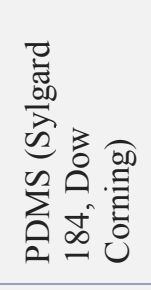 & 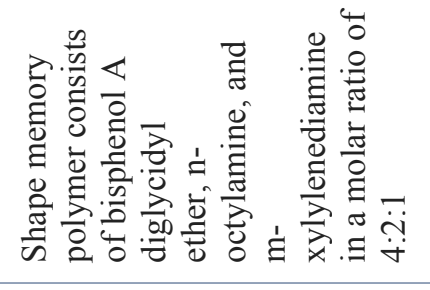 & 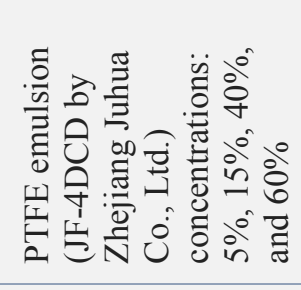 \\
\hline 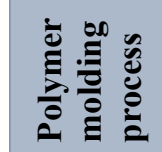 & 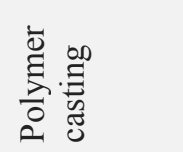 & 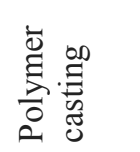 & 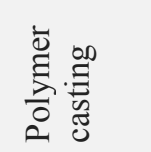 & 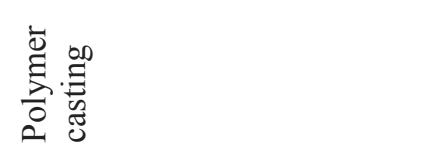 & 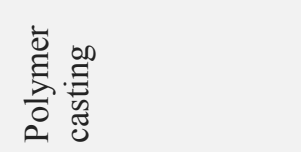 \\
\hline
\end{tabular}




\begin{tabular}{|c|c|c|c|}
\hline Ф্ّ & \pm & $\infty$ & $\bar{\Xi}$ \\
\hline 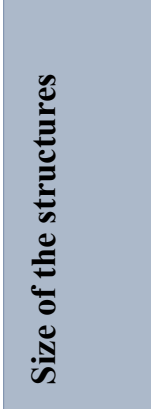 & 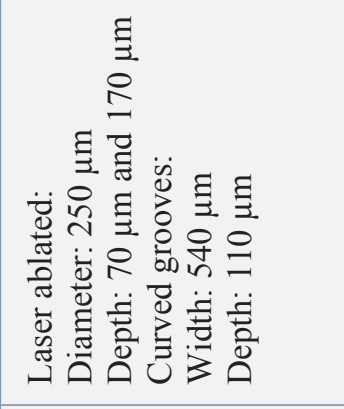 & 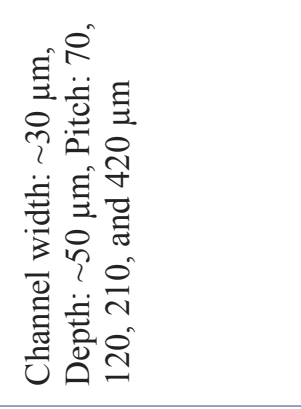 & $\underline{z}$ \\
\hline 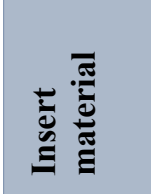 & $\begin{array}{l}\overline{\mathbb{E}} \\
i n\end{array}$ & 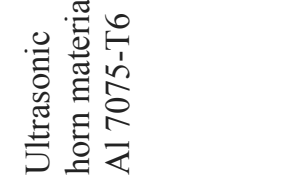 & 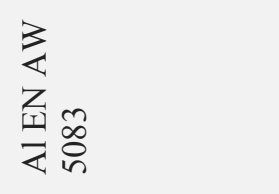 \\
\hline 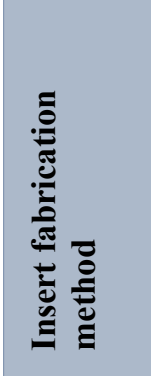 & 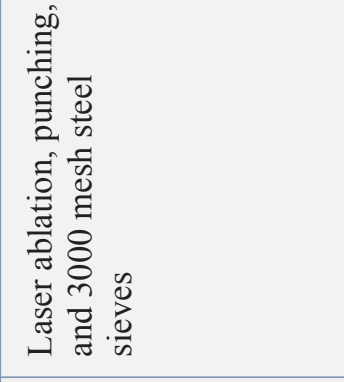 & 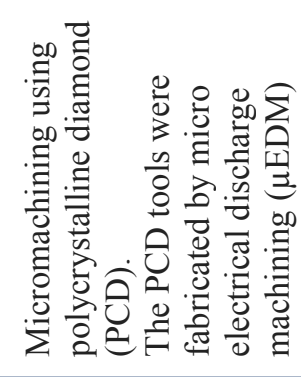 & 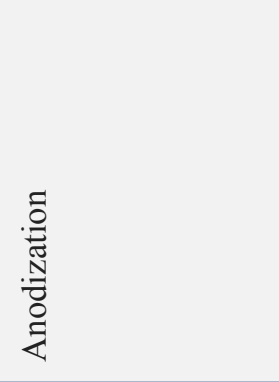 \\
\hline 离 & 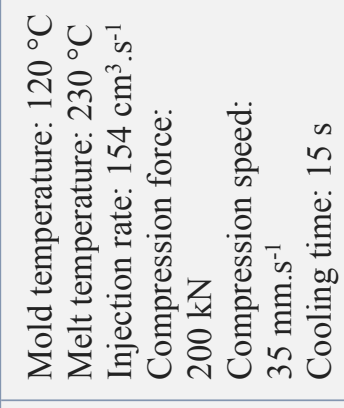 & 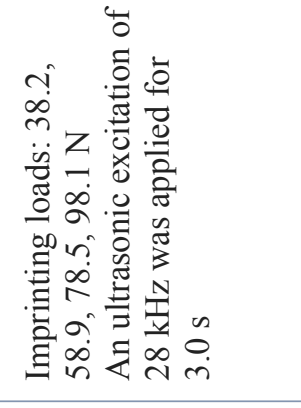 & 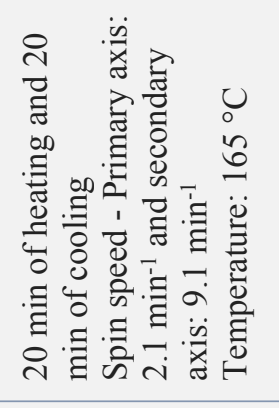 \\
\hline 离 & 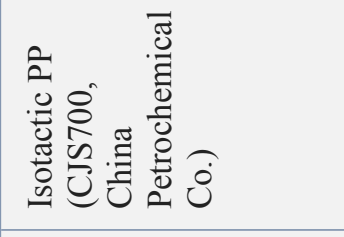 & 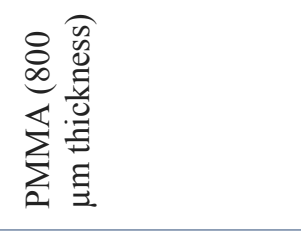 & $\stackrel{112}{2}$ \\
\hline 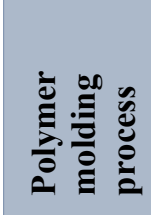 & 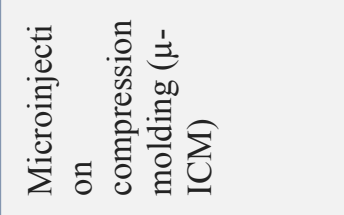 & 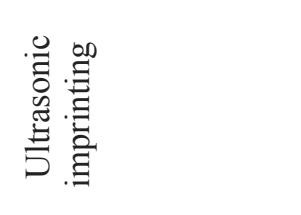 & 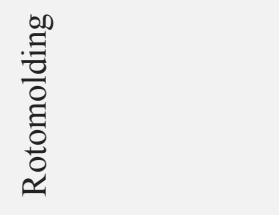 \\
\hline
\end{tabular}

